\title{
Editorials
}

\section{The dangers of compounded bioidentical hormone replacement therapy}

The menopause is a normal life event for women, not an illness or a medical condition. However, the effects of the menopause often have a negative impact on women's wellbeing and quality of life, and are frequently underestimated by noth women and their doctors. Furthermore, the low estrogen levels and other biological changes that occur in menopausal women are also associated with an increased risk of cardiovascular disease, osteoporosis, type 2 diabetes, ${ }^{1}$ and dementia. ${ }^{2}$

Around $75 \%$ of menopausal women experience symptoms, with around onethird of these experiencing severe symptoms which are having a negative effect on their lives, both at home and at work.

Over the past two decades, there has been a huge amount of confusion regarding hormone replacement therapy (HRT). We now have clear, evidence-based guidelines available to ensure women have individualised care and treatment for their perimenopause and menopause. ${ }^{2,3}$

However, many women and healthcare professionals are still worried about the perceived risks of HRT. Much of the negativity regarding HRT stems from the misinterpretation of the Women's Health Initiative (WHI) study in 2002, which led to a worldwide reduction in HRT use. ${ }^{4}$ The subsequent sub-analysis of this study revealed reassuring and positive results to support the use of HRT, especially in younger women. ${ }^{5}$ Other research has supported the National Institute for Health and Care Excellence menopause guidelines that the benefits of HRT outweigh the risks in the majority of women. ${ }^{2}$

\section{THE OPTIMAL TYPE OF HRT}

There is now evidence demonstrating that transdermal estrogen in association with natural micronised progesterone represents one of the optimal HRT regimens. ${ }^{6}$ Transdermal estrogen is the preferred route of administration because, in contrast with oral estrogen, estrogen as a patch or gel is not associated with an increased risk of venous thromboembolism.

"We now have clear, evidence-based quidelines available to ensure women have individualised care and treatment for their perimenopause and menopause.

It can be safely given to women who have a history of migraines, gallbladder disease, diabetes, or who are obese. The optimal progestogen is micronised progesterone which is body identical. This usually has less side effects associated with it compared with the older progestogens. ${ }^{7}$ In addition, there is no increased risk of breast cancer for the first 5 years of taking estrogen with micronised progesterone. ${ }^{8}$

\section{THE RISKS OF HRT}

Most women and healthcare professionals are concerned about the possible risks of breast cancer in women taking HRT. However, the risk is far lower than many realise. Women who take estrogen only HRT (women who have had a hysterectomyl do not have a greater risk of breast cancer. ${ }^{4}$ The recent epidemiological study did not confirm any additional risks with transdermal oestrogen and micronised progesterone.?

Women who take estrogen and a synthetic progestogen may have a very small increased risk of the diagnosis of breast cancer. ${ }^{5}$ However, this increased risk is of a similar magnitude to the risk of breast cancer for women who are overweight, or drinking one or two units of alcohol each night.

Frustratingly, despite this evidence, only around $10 \%$ of women in the UK are currently taking HRT. ${ }^{10}$ Although some women choose not to take HRT or cannot take it for medical reasons, a large proportion of women are declined a prescription for HRT for no valid medical reason. ${ }^{11}$ This is either because the doctor does not know enough about it and been frightened out of prescribing, or the fact that some practices do not prescribe HRT as a cost saving exercise.
Many women are inappropriately given antidepressants instead of HRT which goes against current guidelines. ${ }^{2}$ Often this is due to ignorance (and lack of education) about realising that low oestrogen can cause depressive symptoms.

It is increasingly common that women are seeking HRT from other clinics and healthcare professionals to improve their symptoms and quality of life. Over recent years, there has been an increase in the number of private clinics offering compounded bioidentical HRT to women, which is a major concern. ${ }^{12}$ These are not the same as the 'body identical' hormones or regulated bioidentical HRT.

There are very important differences between different types and formulations of HRT. In the past, estrogen in HRT was derived from pregnant mares' urine. The term 'bioidentical hormones' simply means that they have the same molecular structure as the hormones in the body. Regulated bioidentical hormones are usually referred to as 'body-identical hormones' (rBHRT) to reduce confusion from compounded bioidentical hormones (cBHRT). ${ }^{13}$ Most types of body identical HRT now prescribed are derived from yams, the root vegetable, and are usually available from the NHS, at a cheaper cost than many of the combined oral preparations which contain synthetic progestogens. $^{14}$

\section{COMPOUNDED BIOIDENTICAL HRT}

Compounded bioidentical HRT is not subject to any quality control as it comes under a supplement. They often do not have properly enforced standards of good manufacturing, quality controls, and monitoring, as regulated hormones do. ${ }^{12}$ Many cosmetic and other types of private clinics in the UK and worldwide are offering these hormones to women, often costing vast sums of money. ${ }^{10}$

The hormones are 'compounded' in special pharmacies, so they are custom made to produce tablets, lozenges, and creams, in combination doses 


\section{"Understandably, many women are worried about the Summary of Product Characteristics (SPC) currently in regulated HRT preparations, so they falsely think that these compounded preparations are associated with less risk.}

or preparations that are not routinely available. These hormone preparations are not subjected to the same tests of safety, efficacy, or dosing consistency, as regulated HRT. These preparations may also contain undesirable additives or preservatives, degradation products, process impurities, residual solvents, bacterial endotoxins, or residual amounts of other drugs made in the same pharmacy. ${ }^{12}$

Of more concern, these compounded hormones often have unsubstantiated claims, lack of scientific safety and efficacy data, and lack of quality control surrounding them. ${ }^{15}$ In addition, some of the healthcare professionals who prescribe compounded hormones claim to be able to determine the precise requirements of each woman by undertaking a series of serum and saliva tests. This costly practice has never been substantiated through rigorous research and is not recommended by the menopause societies. $^{13}$

Some of the hormones used in these bioidentical hormones contain hormones that are not approved for women, such as dehydroepiandrosterone (DHEA) or pregnenolone. ${ }^{10}$ Many women are given progesterone creams rather than oral preparations, which are usually not well absorbed in the body. ${ }^{13}$ There is only very scant data available, but the current evidence has failed to show any endometrial protection from progesterone creams or gels. ${ }^{16}$

There is also a concern with the bioidentical oral preparations, as there may be inconsistencies in the quantities of estradiol and other estrogen preparations in compounded preparations. This can lead to an increased risk of venous thromboembolism, as well as increasing the risk of endometrial cancer. ${ }^{10}$

Compounded bioidentical hormone replacement therapy does not carry the safety warnings for estrogen products that are in all prescribed HRT preparations. These were written after the publication of the WHI study ${ }^{4}$ and have not been updated to be in line with current evidence. Understandably, many women are worried about the
Summary of Product Characteristics (SPC) currently in regulated HRT preparations, so they falsely think that these compounded preparations are associated with less risk. ${ }^{17}$

Approved, registered, bioidentical regulated hormonal drugs that are produced in monitored facilities are readily available to prescribe for women in the NHS. This means that it is not appropriate or necessary for women to use the potentially harmful, customised, compounded hormones.

It is essential that clinicians and women are made aware of the potential harms of these hormones, and are not enticed into paying money for expensive unregulated products.

\section{REFERENCES}

1. Slopien R, Wender-Ozegowska E, RogowiczFrontczak A, et al. Menopause and diabetes: EMAS clinical guide. Maturitas 2018; 117: 6-10.

2. The National Institute for Health and Care Excellence. Menopause: diagnosis and management. NG23. 2015. https://www.nice. org.uk/guidance/ng23 (accessed 23 Sep 2019).

3. Baber RJ, Panay N, Fenton A, IMS Writing Group. 2016 IMS recommendations on women's midlife health and menopause hormone therapy. Climacteric 2016; 19(2): 109-150.

4. Rossouw JE, Anderson GL, Prentice RL, et al Risks and benefits of estrogen plus progestin in healthy postmenopausal women: principal results from the Women's Health Initiative randomized controlled trial. JAMA 2002; 288(3): 321-333.

5. Manson JE, Aragaki AK, Rossouw JE, et al. Menopausal hormone therapy and long-term all-cause and cause-specific mortality: the Women's Health Initiative randomized trials. JAMA 2017; 318(10): 927-938.

6. Newson LR, Lass A. Effectiveness of transdermal oestradiol and natural micronised progesterone for menopausal symptoms. $\mathrm{Br}$ J Gen Pract 2018; DOI: https://doi.org/10.3399/ bjgp18X699353.

7. Stanczyk FZ, Hapgood JP, Winer S, Mishell DR Jr. Progestogens used in postmenopausal hormone therapy: differences in their pharmacological properties, intracellular actions, and clinical effects. Endocr Rev 2013; 34(2): 171-208

8. Stute P, Wildt L, Neulen J. The impact of a systematic review. Climacteric 2018; 21(2): 111-122. micronized progesterone on breast cancer risk:

\section{ADDRESS FOR CORRESPONDENCE}

Louise Newson

Winton House, Church Street, Stratford-upon-Avon CV35 7HB, UK

\section{Email: louise.newsonanewsonhealth.co.uk amymenopausedr https://www.newsonhealth.co.uk}

\section{Louise Newson,}

GP and Menopause Specialist, Winton House Stratford-upon-Avon, UK.

\section{Janice Rymer,}

Vice President of the Royal College of Obstetricians and Gynaecologists; Professor of Gynaecology, King's College London; Consultant Gynaecologist, Guy's and St Thomas' NHS Foundation Trust, London, UK.

\section{Provenance}

Freely submitted; externally peer reviewed.

\section{Competing interests}

Louise Newson has had financial relationships las lecturer, writer, member of advisory boards) with various pharmaceutical companies. She is the director of Newson Health Ltd.

DOI: https://doi.org/ 10.3399/bjgp19X706169

9. Collaborative Group on Hormonal Factors in Breast Cancer. Type and timing of menopausal hormone therapy and breast cancer risk: individual participant meta-analysis of the worldwide epidemiological evidence. Lancet 2019; 394(10204):1159-1168.

10. Cumming GP, Currie H, Morris E, et al. The need to do better - are we still letting our patients down and at what cost?. Post Reprod Health 2015; 21(2): 56-62.

11. Newson L, Mair R. Results from the BJFM menopause survey. British Journal of Family Medicine 2018; 6(1)

12. L'Hermite M. Custom-compounded bioidentical hormone therapy: why so popular despite potential harm? The case against routine use. Climacteric 2017; 20(3): 205-211.

13. British Menopause Society. Bioidentical HRT. 2019. https://thebms.org.uk/publications/ consensus-statements/bioidentical-hrt laccessed 23 Sep 2019).

14. The National Institute for Health and Care Excellence. Sex hormones. 2019. https:// bnf.nice.org.uk/treatment-summary/sexhormones.html laccessed 9 Oct 2019].

15. Pinkerton JV. What are the concerns about custom-compounded "bioidentical" hormone therapy? Menopause 2014; 21(12): 1298-1300.

16. Gambrell RD Jr. Progesterone skin cream and measurements of absorption. Menopause 2003; 10(1): 1-3.

17. Thompson JJ, Ritenbaugh C, Nichter M. Why women choose compounded bioidentical hormone therapy: lessons from a qualitative study of menopausal decision-making. BMC Womens Health 2017; 17(1): 97. 